\title{
Establishment and biological characterization of a novel cell line derived from hepatoid adenocarcinoma originated at the ampulla of Vater
}

\author{
NOBUYASU TAKAHASHI ${ }^{1}$, FUMIYO AOYAMA ${ }^{1}$, MASAHIDE HIYOSHI ${ }^{2}$, \\ HIROAKI KATAOKA $^{3}$ and AKIRA SAWAGUCHI ${ }^{1}$
}

\begin{abstract}
Departments of ${ }^{1}$ Anatomy, Ultrastructural Cell Biology, ${ }^{2}$ Surgical Oncology and Regulation of Organ Function,
${ }^{3}$ Section of Oncopathology and Regenerative Biology, Department of Pathology, Faculty of Medicine, University of Miyazaki, Kiyotake, Miyazaki 889-1692, Japan
\end{abstract}

Received November 30, 2013; Accepted January 3, 2014

DOI: 10.3892/ijo.2014.2282

\begin{abstract}
Hepatoid adenocarcinoma is a rare gastrointestinal tumor and mostly reported in the stomach. Effective chemotherapy has yet to be developed to improve poor prognosis. The present study was undertaken to establish a useful cell line derived from a hepatoid adenocarcinoma, possibly leading to a new therapeutic strategy. The new human cell line VAT-39 was established from a metastatic lymph node of a 69-year-old Japanese male patient with hepatoid adenocarcinoma of the ampulla of Vater. The primary tumor and metastatic lymph node were composed of hepatoid adenocarcinoma cells exhibiting immunohistochemical reactivity for alpha-fetoprotein (AFP) and glypican-3 (GPC3). In the metastatic lymph node, Periodic acid-Schiff (PAS) staining clarified diffuse deposition of glycogen in the cytoplasm, indicating analogous characteristics to the primary hepatoid adenocarcinoma. Moreover, VAT-39 cells produced high levels of AFP in the cultured medium, and reverse-transcriptase polymerase chain reaction (RT-PCR) verified increased expression of GPC3 mRNA in this cell line. Further, we evaluated the sensitivity to major chemotherapeutic drugs against the bile duct cancer. Neither 5 -fluorouracil nor gemcitabine showed particular sensitivity to this cell line. The tumorigenicity of the cultured cells was confirmed in athymic nude mice and the histological features of the explanted tumor were similar to the VAT-39 cell line. The present VAT-39 is the first hepatoid adenocarcinoma cell line that originates from the ampulla of Vater and it will be applicable for basic
\end{abstract}

Correspondence to: Professor Akira Sawaguchi, Department of Anatomy, Ultrastructural Cell Biology, Faculty of Medicine, University of Miyazaki, 5200 Kihara, Kiyotake, Miyazaki 889-1692, Japan

E-mail: sawa@fc.miyazaki-u.ac.jp

Key words: cell line, hepatoid adenocarcinoma, $\alpha$-fetoprotein, glypican-3 biological studies searching for new strategies of molecular targeted chemotherapy to this disease.

\section{Introduction}

Hepatoid adenocarcinoma is a rare gastrointestinal tumor and mostly reported in the stomach. The first case of $\alpha$-fetoprotein (AFP)-producing gastric carcinoma was reported in 1970 by Bourreille et al (1). It has been generally accepted to categorize the hepatoid adenocarcinoma as gastric carcinoma with a feature of hepatic differentiation complicated with high serum AFP level, proposed by Ishikura et al (2). Besides the stomach, to our knowledge, it has also been described in colon (3), pancreas (4), lung (5), esophagus (6), papilla of Vater (7), urinary bladder (8), renal pelvis (9), ovaries (10), uterus (11) and the cervix (12).

Hepatoid adenocarcinoma is pathologically diagnosed by morphological similarity to the hepatocellular carcinoma (HCC), and immunohistochemical reactivity for AFP and remarkable elevation of serum AFP are crucial characteristics to the diagnosis. Clinically, hepatoid adenocarcinoma shows particular characteristics as metastasis to the liver and lymph nodes. Additionally, effective chemotherapy has not been established as yet suggesting poor prognosis. More efficient strategy for the treatment of this malignant tumor is necessary since it is not so rare. The incidence rates of $2.7-5.4 \%$ (13-15), of AFP-producing primary gastric carcinoma indicates the infrequency of hepatoid adenocarcinoma. It should be noted that the currently used AFP-producing hepatoid adenocarcinoma cell lines, Takigawa (16), FU 97 (17), ISt-1 (18), OSS and TTS (19), were derived from the stomach. In considering various sites of primary tumor and its malignant characteristics, new cell lines derived from non-gastric cancers are required to develop new strategies.

Herein we describe the establishment of a novel hepatoid adenocarcinoma cell line, designated as VAT-39, and its biological characteristics. This cell line will be a useful tool to clarify further characteristics of hepatoid adenocarcinoma and to develop a new treatment strategy for this refractory disease. 


\section{Materials and methods}

Primary culture. A 69-year-old Japanese man consulted a local doctor because of a right flank pain. He was referred to our hospital in 2009 for further examination and treatment. Laboratory values upon admission indicated liver dysfunction and obstructed jaundice. Endoscopic retrograde cholangiopancreatography and abdominal computed tomography suggested adenocarcinoma of the ampulla of Vater with lymph node metastasis. No metastasis to the liver and the other organs was observed. On the basis of these findings, pylorus-preserving pancreatoduodenectomy with lymph node dissection was performed (Fig. 1A). Pathological diagnosis was hepatoid adenocarcinoma of the ampulla of Vater with lymph node metastasis (Fig. 1B) considering the positive immunoreactivity for AFP (Fig. 1C). Small part of the viable lesion of the lymph node metastasis was resected surgically during an operation, rinsed with phosphate-buffered saline (PBS), and minced with scissors, followed by digestion in $1 \mathrm{mg} / \mathrm{ml}$ collagenase (Wako Pure Chemical Industries, Ltd., Osaka, Japan), 1000 PU/ml dispase (Godo Shusei, Tokyo, Japan) in the mixture of RPMI-1640 (Nissui, Tokyo, Japan) and Ham's F12 (Nissui) at the rate of $1: 1$ at $37^{\circ} \mathrm{C}$ for $4 \mathrm{~h}$. The remaining part was used for pathological diagnosis. Then the solution was centrifuged at $700 \mathrm{rpm}$ for $3 \mathrm{~min}$ and the pellet was resuspended in the same medium supplemented with $10 \%$ heat-inactivated fetal bovine serum (FBS) (JRH Biosciences, KS, USA), 100 IU/ml penicillin (Meiji Seika Pharma Co., Ltd., Tokyo, Japan), $100 \mu \mathrm{g} / \mathrm{ml}$ streptomycin (Meiji Seika Pharma Co., Ltd.), 20 mM N-2-hydroxyethyl piperazine-N'-2-ethane sulfonic acid (HEPES) (Nakalai, Kyoto, Japan), pH 7.4. The flasks were cultured in a fully humidified atmosphere of $5 \%$ $\mathrm{CO}_{2}$ in air at $37^{\circ} \mathrm{C}$. Informed consent was obtained from this patient and the protocol was approved by the ethics board of the Faculty of Medicine, University of Miyazaki. Mycoplasma infection was examined by a PCR Mycoplasma Detection kit (Takara Bio Inc., Shiga, Japan).

Growth characteristics. Growth curves were established by seeding $1 \times 10^{5}$ cells $/ 5 \mathrm{ml}$ in growth medium onto $60-\mathrm{mm}$ culture dishes. Triplicate dishes were harvested and counted daily. Throughout the entire procedure, cell viability was determined by means of the trypan blue exclusion method. Doubling time was determined during the exponential phase of growth.

Karyotyping and short tandem repeat (STR) analysis. Exponentially growing cultures of the cell line, passage number 50, was harvested for chromosome preparations with standard procedures by SRL (Tokyo, Japan). Fifty cells were analyzed for chromosome number and the Giemsa banding technique for karyotype analysis. STR profiling at the passage number 1 and 50 were performed by Takara Bio Inc. to identify the cross-contamination of another cell line.

Morphological analysis. For light microscopy, VAT-39 cells were cultivated on Chamber Slide (Nunc Inc., IL, USA) and fixed with $4 \%$ paraformaldehyde in $0.1 \mathrm{M}$ phosphate buffer (PB) for 30 min at room temperature (RT). After washing with $\mathrm{PB}$, the cells were observed with hematoxylin-eosin (H\&E)
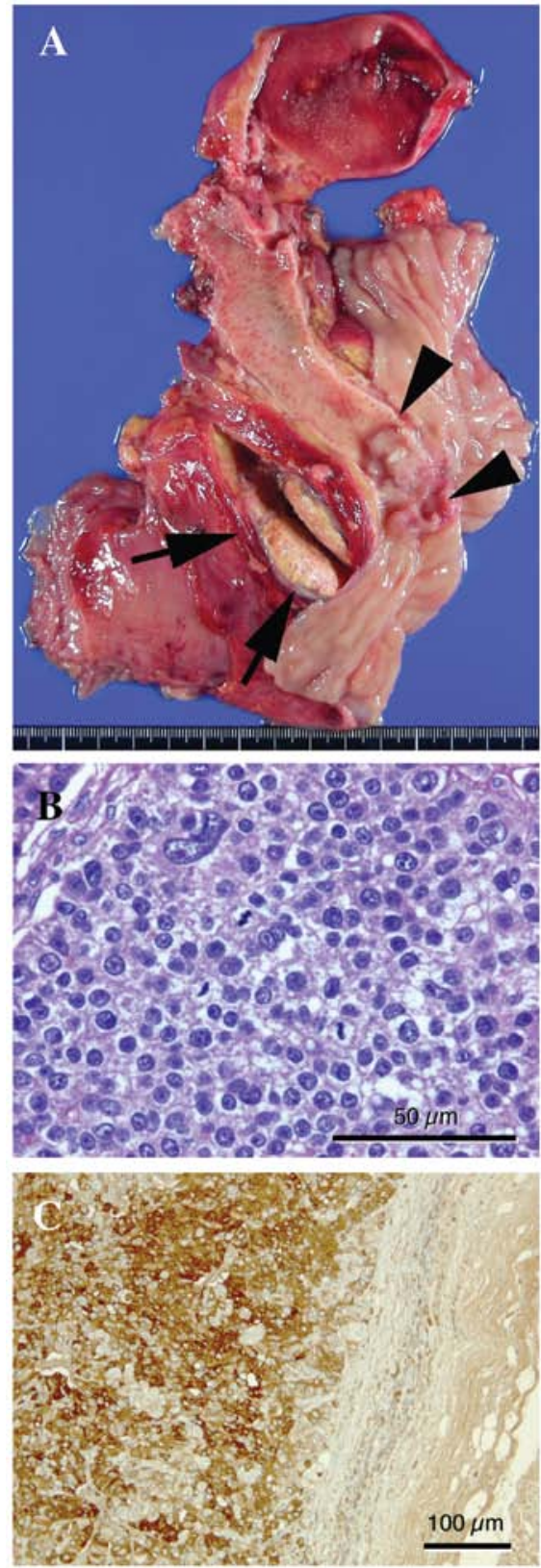

Figure 1. Surgical pathology of the primary tumor. (A) The tumor was located at the ampulla of Vater with invasions into the common bile duct and the major pancreatic duct (arrowheads). Arrows indicate a large lymph node metastasis with central necrosis. (B and C) H\&E staining and immunohistochemical localization of AFP in the lymph node metastasis, respectively.

or Periodic acid-Schiff (PAS) staining to examine their morphology and the existence of glycogen, respectively.

For electron microscopy, high-pressure freezing (HPF) technique was applied for fine structural observation $(20,21)$. In brief, VAT-39 cells were cultivated on sterilized $10 \mu \mathrm{m}$-thin stainless foil (YUS205-M1, Nippon Steel, Tokyo, Japan). At semi-confluency, the attached VAT-39 cells on the stainless foil were immediately cryofixed in the HPF machine (HPM010, BAL-TEC, Liechtenstein). The assembly with cryofixed cells was transferred to $1 \mathrm{ml}$ of freeze substitution medium ( $1 \%$ osmium tetroxide in acetone), and then freeze substituted in a Leica AFS machine (Leica, Vienna, Austria). After embedding into epoxy resin, ultrathin sections $(60-80 \mathrm{~nm})$ were cut and stained with uranyl acetate and lead 
citrate to be observed in a transmission electron microscope (HT7700, Hitachi, Tokyo, Japan).

Electron microscopic localization of cytoplasmic glycogen was performed by means of periodate-thiocarbohydrazidesilver proteinate (PA-TCH-SP) method. Briefly, the VAT39 cells cultivated on the micro-cover glass (thickness no. 5, Matsunami, Osaka, Japan) (22) were fixed with a mixture of $2 \%$ paraformaldehyde and $2.5 \%$ glutaraldehyde in $0.1 \mathrm{M}$ PB for $2 \mathrm{~h}$ at RT. After washing with in PBS, without postfixtaion by $1 \%$ osmium tetroxide, the cells were dehydrated and embedded in epoxy resin. Ultrathin sections mounted on gold meshes were treated in $1 \%$ sodium periodate (Wako Pure Chemical Industries, Ltd.) for 30 min followed by $1 \%$ thiocarbohydrazide (Sigma-Aldrich, MO, USA) for $1 \mathrm{~h}$. After washing, the sections were incubated in $1 \%$ silver protein (Merck, Germany) for $1 \mathrm{~h}$ and observed as described above.

Immunohistochemistry of AFP. Conventionally prepared paraffin sections were deparaffinized, and incubated in $0.3 \% \mathrm{H}_{2} \mathrm{O}_{2}$ in methanol to block endogenous peroxidase for 30 min. After rinsing in PBS, the sections were treated with $1 \%$ bovine serum albumin (BSA) in PBS for $20 \mathrm{~min}$, and then incubated with a polyclonal rabbit anti-human AFP (Dako, Tokyo, Japan; 1:10 diluted with 1\% BSA in PBS) for $1 \mathrm{~h}$ at RT. After washing with PBS, the sections were incubated with biotinylated horse anti-rabbit IgG (Vector Laboratories, CA, USA; diluted 1:300 with 1\% BSA in PBS) for $40 \mathrm{~min}$ at RT. After washing with PBS, the sections were incubated in a freshly prepared solution of avidin-biotinylated horseradish peroxidase complex (ABC) kit (Vector Laboratories) for $30 \mathrm{~min}$ (23), and then peroxidase reaction was developed by incubating in $0.05 \%$ 3,3-diaminobenzidine tetrahydrochloride in $0.05 \mathrm{M}$ Tris buffer, $\mathrm{pH} 7.6$, containing $0.001 \%$ $\mathrm{H}_{2} \mathrm{O}_{2}$ for 5-10 min. After washing, the sections were briefly counterstained with hematoxylin.

Detection of AFP in the serum and the culture medium. The sera, preoperative and postoperative conditions, were collected as a routine follow up of operation. The supernatants of VAT-39 at passage 50 were harvested after 24, 48 and 72-h culture in $5 \mathrm{ml}$ of serum-free media in a $25 \mathrm{~cm}^{2}$ flask. The AFP concentrations in these samples were measured by Architect AFP using Architecto i200SR (Abbott, Chiba, Japan).

RT-PCR of HCC related gene. Human biliary tract cancer cell lines (HuCCt1, HuH-28, TFK-1, TKKK, TGBC2TKB, TGBC14TKB and TGBC18TKB) were obtained from Riken Cell Bank (Tsukuba, Japan). The two other human biliary tract cancer cell lines (IHGGK and G415) were obtained from Tohoku University (Miyagi, Japan). Total RNAs were extracted with TRIzol ${ }^{\mathrm{TM}}$ reagent (Invitrogen, Carlsbad, CA, USA), followed by Cloned DNase I (Takara Bio. Inc.) treatment and phenol/chloroform/isoamylalcohol extraction. For RT-PCR, $6 \mu \mathrm{g}$ of total RNA was reverse transcribed with a mixture of oligo (dT) and random primer using 200 units of ReverTra Ace $^{\circledR}$ (Toyobo, Osaka, Japan), and 1/90 of the resultant cDNA was processed for each PCR with $0.25 \mu \mathrm{M}$ of both reverse and forward primers and 1.25 units of HotStar ${ }^{\circledR}$ Taq DNA polymerase (Qiagen, Tokyo, Japan). For detection of hepatoid adenocarcinoma-related gene mRNA, the following primers were designed: AFP, sense 5'-GACATCCTCAGCTTGCT GTC-3' and antisense 5'-GAGGCCGCAGCTTCGCTTTG-3' (173 bp); GPC3, sense 5'-GCAGGAAAGCTGACCACCAC-3' and antisense 5'-GACATGGTTCTCAGGAGCTGG-3' (419 bp); glyceraldehydes-3-phosphate dehydrogenase (GAPDH), sense 5'-GTGAAGGTCGGAGTCAACG-3', and antisense 5'-GGT GAAGACGCCAGTGGACTC-3' (300 bp). The PCR products were analyzed by $1.5 \%$ agarose gel electrophoresis.

In vitro sensitivity to chemotherapeutic agents. We evaluated the effect of several chemotherapeutic reagents, generally used to the patient of biliary tract cancer, on the growth of VAT-39 at the passage number 50. Gemcitabine, 5-fluorouracil, epirubicin and mitomycin $\mathrm{C}$ were purchased from Wako Pure Chemical Industries, Ltd.; paclitaxel, oxaliplatin and doxorubicin were from Nakalai; cisplatin was from Sigma-Aldrich. The VAT-39 cells $\left(1 \times 10^{4}\right)$ were seeded in 96-well plates and cultivated overnight in $100 \mu \mathrm{l}$ of the same medium containing $10 \% \mathrm{FBS}$. The medium was removed and replaced with the same medium containing various concentrations of the chemical agents. After $24 \mathrm{~h}$ incubation, $10 \mu \mathrm{l}$ of Cell Counting Kit-8 (Dojindo, Kumamoto, Japan) was added to each well. Following further $3 \mathrm{~h}$ incubation, the absorbance at $450 \mathrm{~nm}$ was monitored using ImmunoMini NJ-2300 (Biotec Co. Ltd., Tokyo, Japan).

In vivo experiment. Tumorigenicity and metastatic potential of VAT-39 cells were analyzed using 6 weeks old BALB/c athymic mice (Kyudo, Kumamoto, Japan). After trypsinization of cultured cells by $0.25 \%$ trypsin and $0.02 \%$ ethylenediamine tetraacetic acid (TE, Sigma-Aldrich), the cells were centrifuged immediately at $1000 \mathrm{x}$ g for $5 \mathrm{~min}$, and the resuspended cells $\left(1 \times 10^{6}\right.$ in $0.2 \mathrm{ml}$ PBS $)$ were injected subcutaneously at the abdominal flank. At 8 weeks or when the mice became moribund, they were sacrificed or necropsied. Under general anesthesia using diethyl ether, the xenograft, brain, lung, liver, kidneys and gastrointestinal tract were harvested and examined under a dissecting microscope. Tumor volume was calculated weekly using the formula, length $\mathrm{x}$ (width) ${ }^{2} \times 0.5$. For light microscopy, xenografted tumors were fixed with $4 \%$ paraformaldehyde in $0.1 \mathrm{M} \mathrm{PB}$ at $4^{\circ} \mathrm{C}$ overnight, and embedded in paraffin. The sections were stained with H\&E.

All animal procedures were carried out under protocols approved by the University of Miyazaki Animal Research Committee, in accordance with international guiding principles for biomedical research involving animals.

\section{Results}

Establishment of the VAT-39 cell line and light microscopic characterization. The tumor cells formed colonies surrounded by fibroblasts in two months of primary culture. The fibroblasts were eliminated by a weak trypsin and TE treatment for one month. The first passage was done at a split ratio of 1:4. The cell line was designated as VAT-39, and it has already undergone more than 100 passages.

The VAT-39 cells proliferated well in culture media containing $10 \%$ FBS. The polygonal cells with prominent nucleoli formed adhesive sheet-structures as shown in phasecontrast microscopy (Fig. 2A). Morphological findings of 


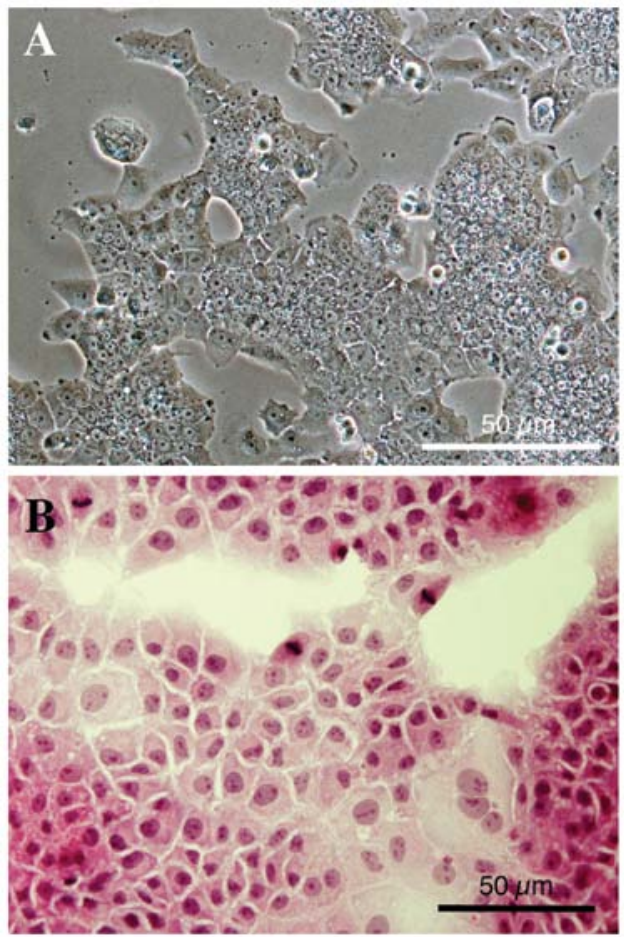

Figure 2. Morphological analysis of the established VAT-39 cell line. (A) Phase-contrast microscopy of VAT-39 cells at passage 50. (B) H\&E staining of VAT-39 cultured on the chamber slide.

VAT-39 (Fig. 2B) were mostly in accordance with those of the lymph node metastasis (Fig. 1B) in which mitotic figures were frequently seen. Growth characteristics were determined at passages 1 and 50. The doubling times at passage 50 were $34 \mathrm{~h}$ (data not shown). The cell line was free from mycoplasma infection.

STR and karyotype analysis. The STR analysis was performed at passages 1 and 55 of the VAT-39 cells, and the obtained STR profile $\sim 10$ loci and detected peaks were: AMEL (X), CSF1PO (12), D13S317 (11), D16S539 (9,12), D21S11 (30), D5S818 (12), D7S820 (12,13), TH01 (9), TPOX (8,11), vWA $(14,17)$. The STR analysis at passage 1 was identical to that of 55, which confirmed that VAT-39 cell lines maintained the same genetic feature without possible contamination.

The number of chromosomes was between 50-54 at passage 50 with a modal chromosome number 53 . The result of karyotype analysis of 10 cells were as follows; $\mathrm{X},-\mathrm{Y},+\operatorname{add}(1)(\mathrm{p} 11)$, add(1)(q21), +del(3)(p11), der(3)add(3)(q21)del(3)(q?), add(7) (p11.2), add(9)(p13), der(11)add(11)(p11.2)add(11)(q23), der(11) add(11)(p15)add(11)(q23), add(13)(p11.2)x2, -14, +del(16)(p?), del(16)(q?), add(19)(p13), -20, add(21)(q22), +mar1, +mar2, + mar3, +mar4x 2 . No change was observed in chromosome number 4 and $\mathrm{X}$ where the $A F P$ and $G P C 3$ genes are located, respectively.

Transmission electron microscopy and detection of glycogen granules. Transmission electron microscopic study by HPF revealed electron lucent granules in the cytoplasm of VAT-39 cells (Fig. 3A), suggesting accumulations of glycogen granules. Light microscopy by PAS staining demonstrated strongly stained numerous granules in the cytoplasm (Fig. 3B). At
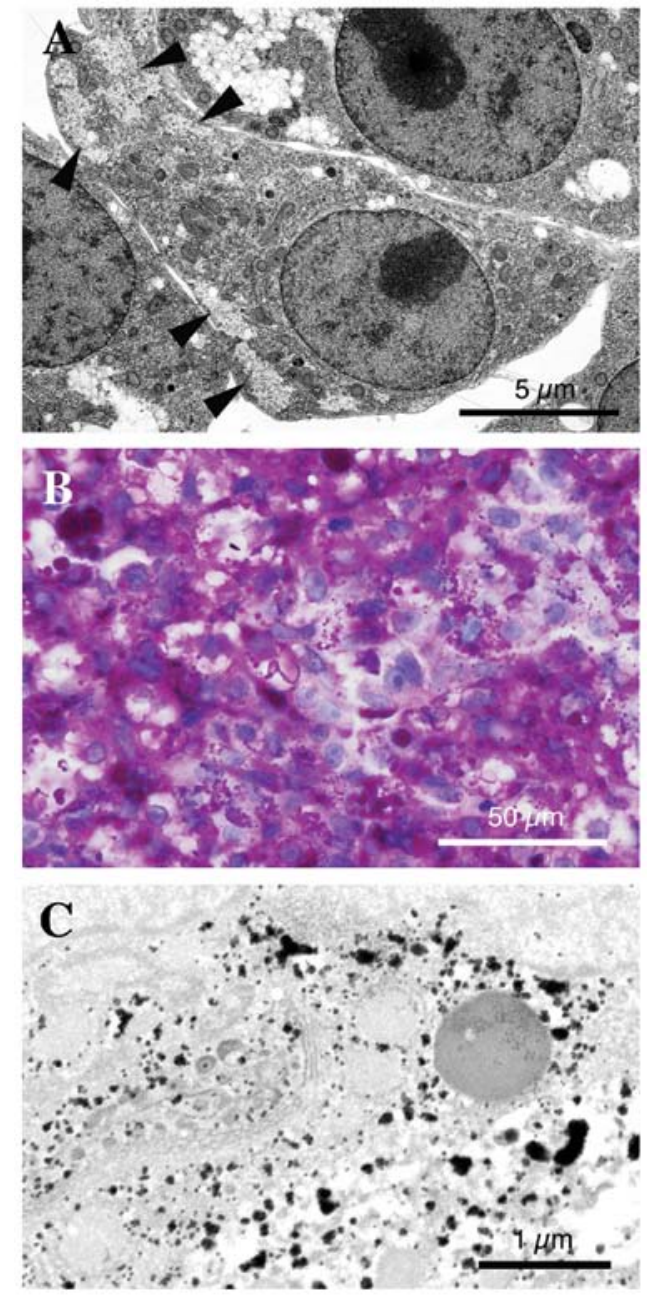

Figure 3. Detection of glycogen granules. (A) Transmission electron micrographs of VAT-39 cells cryofixed by HPF. Note the electron lucent granules in the cytoplasm (arrowheads). (B) PAS staining of explanted VAT-39 cells. (C) Electron micrograph by the PA-TCH-SP method.

the electron microscopic level, PA-TCH-SP method clarified the accumulation of glycogen in the electron lucent granules (Fig. 3C).

AFP expression in the cells, culture media and sera. Immunohistochemistry of AFP demonstrated a distinct immunoreactivity around the perinuclear region of VAT-39 cells (Fig. 4A). The expression of AFP mRNA in VAT-39 cells was evaluated by RT-PCR (32 cycles of amplification), in comparison with various cell lines derived from biliary tract cancer. As a result, the VAT-39 cell line exceptionally expressed AFP mRNA (Fig. 4B). The expression was confirmed in the lymph node metastasis, from which the VAT-39 cell line was established, as well as in the VAT-39 cells of varying passage numbers (Fig. 4C). Moreover, the VAT-39 cell line and the lymph node metastasis also expressed GPC3 mRNA (Fig. 4B and C) that is highly expressed in HCC. The AFP protein concentrations were highly elevated in the culture media depending on the culture period (Table IB).

Although the APF protein concentration in the preoperative serum indicated a remarkably high level, the concentration was drastically decreased in the postoperative serum (Table IA). 

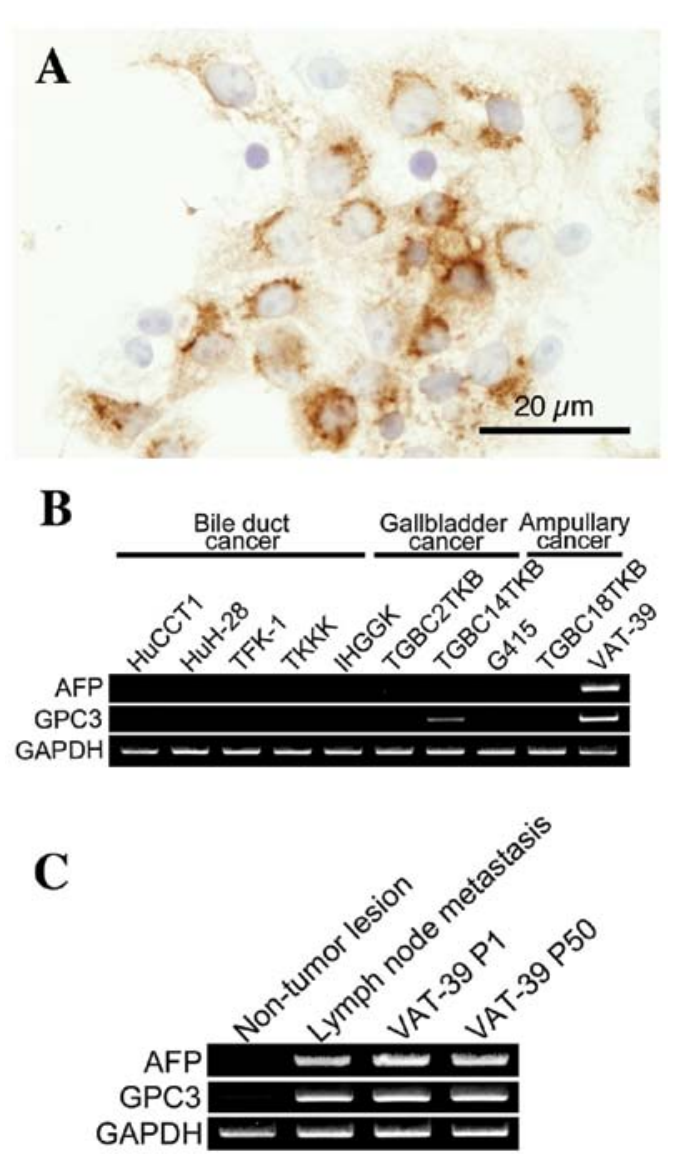

Figure 4. Detection of AFP and GPC3. (A) Immunohistochemical localization of AFP in VAT-39 cell line cultured on the chamber slide. (B and C) RT-PCR of AFP and GPC3 mRNA. (B) Note the expression of AFP and GPC3 mRNA by VAT-39 cell lines among the 10 biliary tract cancer cell lines. (C) AFP and GPC 3 expressions are shown in the primary lymph node metastasis and VAT-39 cell line at passages 1 and 50 .

Taken together, the elevated serum AFP was considered to be secreted from the tumor, and this phenotype was wellpreserved in this established cell line.

Chemotherapeutic sensitivity. The VAT-39 cells were subjected to various chemotherapeutic reagents to evaluate their sensitivities to each reagent concerned with 50\% inhibition concentration (Table II). As a result, the VAT-39 cell line exhibited no sensitivity to 5-FU and gemcitabine.

Transplantation to the nude mouse. Tumorigenicity was tested by subcutaneous injection of VAT-39 cells at the abdominal flank of nude mice. The cells grew rapidly to form solid tumor masses, which were detected within 4 weeks (Fig. 5A, inset). The tumor doubling time was calculated as 2.5 days (data not shown). The VAT-39 cell pellets showed $100 \%$ tumorigenicity in all the transplanted mice ( $\mathrm{n}=5$; data not shown). It should be noted that obvious tumor mass necrosis was seen on a cut surface of the xenografted tumor. Histopathology demonstrated central necrosis, surrounded by viable polygonal tumor cells in the peripheral region. The viable cells formed sheet-structures, showing hyperchromatic nuclei, prominent nucleoli, foamy and clear cytoplasm, and numerous mitotic figures (Fig. 5A). The expression of AFP was also noted in the explanted tumor of the nude mouse (Fig. 5B), preserving the characteristics of AFP
Table I. Concentrations of AFP in preoperative, postoperative sera and culture media.

\begin{tabular}{lc} 
A, Sera & \\
\hline Serum & Concentration $(\mathrm{ng} / \mathrm{ml})$ \\
\hline Preoperation & 1,955 \\
Postoperation (12 days) & 255 \\
Postoperation (28 days) & 46.4 \\
\hline B, Culture media & \\
\hline Media & Concentration (ng/ml) \\
\hline Serum-free medium & 0.4 \\
Non-cultured medium $+10 \%$ FBS & 1.8 \\
Cultured medium & 7,370 \\
(after 24 h of incubation) & 10,106 \\
Cultured medium & \\
(after 48 h of incubation) & 12,722 \\
Cultured medium & \\
(after 72 h of incubation) &
\end{tabular}
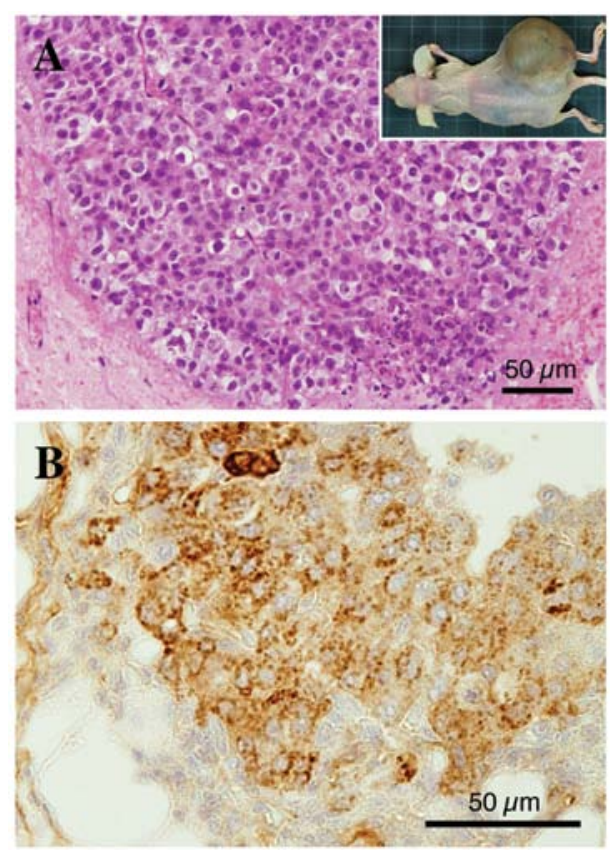

Figure 5. In vivo experiments. (A) H\&E stain of the xenograft cells explanted in the abdominal flank of athymic mice (inset). (B) Immunohistochemical localization of AFP in the explanted tumor.

expression. These findings were consistent with the original tumor and lymph node metastasis (Fig. 1B). In the explanted mice, no metastatic lesion was identified in the other organs.

\section{Discussion}

Hepatoid adenocarcinoma is a rare gastrointestinal tumor and mostly reported in the stomach. Ishikura et al (2) proposed to 
Table II. Fifty percent-inhibition concentration $\left(\mathrm{IC}_{50}\right)$ of various chemotherapeutic reagents.

\begin{tabular}{lc}
\hline Reagents & $\mathrm{IC}_{50}(\mu \mathrm{g} / \mathrm{ml})$ \\
\hline 5-FU & N.D. \\
Gemcitabine & N.D. \\
Paclitaxel & 21.2 \\
Mitomycin C & 9.2 \\
Oxaliplatin & 35.9 \\
Doxorubicin & 7.1 \\
CDDP & 58.9 \\
Epirubicin & 8.0 \\
\hline
\end{tabular}

N.D., not detected.

categorize the hepatoid adenocarcinoma as gastric carcinoma with a feature of hepatic differentiation complicated with high serum AFP level. Clinically, it is also characterized by the extensive hematogenous metastasis to the liver and early involvement of lymph nodes (24).

Human AFP, molecular mass of $69 \mathrm{kDa}(25)$, is a tumor associated fetal protein synthesized in the fetal liver, yolk sac and hepatomas. In considering various primary sites of hepatoid adenocarcinoma, new useful cell lines derived from non-gastric cancer are required to develop a new strategy against its malignant characteristics. However, to our knowledge, currently available AFP-producing cell lines were derived from gastric cancer, and non-gastric hepatoid adenocarcinoma cell line has not been described, thus far. The present VAT-39 cell line is the first cell line derived from hepatoid adenocarcinoma of the ampulla of Vater, and its explant potential has successfully confirmed in athymic nude mice.

A principal function of liver is the synthesis of glycogen, followed by its storage, breakdown, and release into the circulation as glucose. Nagai et al (26) reported that the glycogen granules and hyaline globules were common features in hepatoid adenocarcinoma. In this study, the existence of glycogen granules was clearly identified in the hepatoid adenocarcinoma cell lines, VAT-39, at both light and electron microscopic level.

The poor prognosis remains to be solved in this refractory disease. Takahashi et al (19) elucidated an angiogenesisdependent behavior of AFP-producing gastric carcinoma. In fact, treatment with anti-AFP antibody provided downregulation of angiogenesis, suggesting that AFP itself is likely to upregulate angiogenesis, and the anti-angiogenic effects by antibody treatment may inhibit metastasis, especially to the liver (19). It has been reported that AFP-positive group showed higher incidence of lymph node metastasis, deeper invasion into the gastric wall, higher frequency of advanced stage, marked lymphatic invasion, and higher rate of liver metastasis in comparison to AFP-negative group (13). Another study reported that liver metastasis occurred in $72 \%$ of AFP-positive patients whose mortality reached $100 \%$ within 2 years (15). Although the function of AFP is not completely understood, a control of AFP expression may improve the poor prognosis. The VAT-39 cell line retains a large amount of AFP produc- tion, similar to Takigawa and FU97 cell lines $(16,17)$, even after 50 passages. Therefore, the VAT-39 cell line would be a useful tool for elucidating the function and expression of AFP to develop a new therapeutic strategy.

It has been recently reported that circumferential membranous GPC3 immunoreactivity in $\mathrm{HCC}$ indicated a poor prognosis particularly in patients with hepatitis $\mathrm{C}$ virus infection (27). The GPC3 is thought to be a sensitive marker for hepatoid adenocarcinoma (28), and the level of GPC3 induction is supposed to be controlled by alpha-fetoprotein regulator 2 (Afr2) (29). A monoclonal antibody, named GC33, was recently developed against human GPC3 (30). The GC33 antibody recognizes a GPC 3 ectodomain and provides significant antitumor activity in vivo by inducing antibodydependent cellular cytotoxicity $(30,31)$. Although expression of neither AFP nor GPC3 mRNA was identified in the biliary tract cancer cell lines, the present VAT-39 cell line exhibited extraordinary expression of both AFP and GPC 3 mRNA as high as the original lymph node metastasis used for the primary culture. In this connection, the GC33 might be a candidate for promising antitumor antibody to improve the poor prognosis of hepatoid adenocarcinoma, and the VAT-39 cell line would be a useful tool to examine any potential effect of GC33 on this refractory disease.

In summary, the present establishment and biological characterization of VAT-39 cell line will provide a novel experimental model for biological investigations searching for a new therapy to treat hepatoid adenocarcinoma.

\section{Acknowledgements}

We thank Yoshiteru Goto (Division of Electron Microscopy in Frontier Science Research Center, University of Miyazaki) and Yasuyo Todaka (Department of Anatomy, Ultrastructural Cell Biology, Faculty of Medicine, University of Miyazaki) for their expert assistance. This study was supported by Grantsin-Aids for Scientific Research from the Japan Society for the Promotion of Science (nos. 23791552 and 30336292).

\section{References}

1. Bourreille J, Metayer P, Sauger F, Matray F and Fondimare A: Existence of alpha fetoprotein during gastric-origin secondary cancer of the liver. Presse Med 78: 1277-1278, 1970 (In French).

2. Ishikura H, Kirimoto K, Shamoto M, et al: Hepatoid adenocarcinomas of the stomach. An analysis of seven cases. Cancer 58: 119-126, 1986.

3. Lattes C, Carella R, Faggioli S, Gabusi E and Grigioni WF: Hepatoid adenocarcinoma of the rectum arising in ulcerative colitis: report of a case. Dis Colon Rectum 43: 105-108, 2000.

4. Paner GP, Thompson KS and Reyes CV: Hepatoid carcinoma of the pancreas. Cancer 88: 1582-1589, 2000.

5. Arnould L, Drouot F, Fargeot P, et al: Hepatoid adenocarcinoma of the lung: report of a case of an unusual alpha-fetoproteinproducing lung tumor. Am J Surg Pathol 21: 1113-1118, 1997.

6. Motoyama T, Higuchi $M$ and Taguchi J: Combined choriocarcinoma, hepatoid adenocarcinoma, small cell carcinoma and tubular adenocarcinoma in the oesophagus. Virchows Arch 427: 451-454, 1995.

7. Gardiner GW, Lajoie G and Keith R: Hepatoid adenocarcinoma of the papilla of Vater. Histopathology 20: 541-544, 1992.

8. Sinard J, Macleay L Jr and Melamed J: Hepatoid adenocarcinoma in the urinary bladder. Unusual localization of a newly recognized tumor type. Cancer 73: 1919-1925, 1994.

9. Ishikura $\mathrm{H}$, Ishiguro T, Enatsu $\mathrm{C}$, et al: Hepatoid adenocarcinoma of the renal pelvis producing alpha-fetoprotein of hepatic type and bile pigment. Cancer 67: 3051-3056, 1991. 
10. Devouassoux-Shisheboran M, Schammel DP and Tavassoli FA: Ovarian hepatoid yolk sac tumours: morphological, immunohistochemical and ultrastructural features. Histopathology 34: 462-469, 1999.

11. Toyoda H, Hirai $\mathrm{T}$ and Ishii E: Alpha-fetoprotein producing uterine corpus carcinoma: a hepatoid adenocarcinoma of the endometrium. Pathol Int 50: 847-852, 2000.

12. Shintaku M,Kariya M, Shime $\mathrm{H}$ and Ishikura $\mathrm{H}$ : Adenocarcinoma of the uterine cervix with choriocarcinomatous and hepatoid differentiation: report of a case. Int J Gynecol Pathol 19: 174-178, 2000.

13. Kono K, Amemiya H, Sekikawa T, et al: Clinicopathologic features of gastric cancers producing alpha-fetoprotein. Dig Surg 19: 359-365, 2002

14. Takahashi Y, Mai M, Ogino T, Ueda H, Sawaguchi K and Ueno M: Clinicopathological study of AFP producing gastric cancer - significance of AFP in gastric cancer. Nihon Geka Gakkai Zasshi 88: 696-700, 1987 (In Japanese).

15. Chang YC, Nagasue N, Abe S, Taniura H, Kumar DD and Nakamura T: Comparison between the clinicopathologic features of AFP-positive and AFP-negative gastric cancers. Am J Gastroenterol 87: 321-325, 1992.

16. Sekiguchi M, Fujii Y, Saito A, et al: Alpha-fetoprotein-producing gastric carcinoma: biological properties of a cultured cell line. J Gastroenterol 30: 589-598, 1995.

17. Matsuda M, Watanabe A, Sawada H, et al: Establishment of an alpha-fetoprotein-producing cell line derived from gastric cancer. In Vitro Cell Dev Biol Anim 35: 555-557, 1999.

18. Terashima M, Ikeda K, Maesawa C, et al: Establishment of an alpha-fetoprotein-producing gastric cancer cell line in serumfree media. Jpn J Cancer Res 82: 883-885, 1991.

19. Takahashi Y, Ohta T and Mai M: Angiogenesis of AFP producing gastric carcinoma: correlation with frequent liver metastasis and its inhibition by anti-AFP antibody. Oncol Rep 11: 809-813, 2004

20. Sawaguchi A, McDonald KL and Forte JG: High-pressure freezing of isolated gastric glands provides new insight into the fine structure and subcellular localization of $\mathrm{H}^{+} / \mathrm{K}^{+}$-ATPase in gastric parietal cells. J Histochem Cytochem 52: 77-86, 2004.

21. Sawaguchi A, Aoyama F, Ide S, Goto Y and Suganuma T: A new device for high-pressure freezing of cultured cell monolayer using 10-micron-thin stainless discs as both culture plate and specimen carrier. J Electron Micros 57: 203-206, 2008.
22. Sawaguchi A, Aoyama F, Ide S and Suganuma T: Capsulesupporting ring: a new device for resin embedding of glass-mounted specimens. J Microsc 234: 113-117, 2009.

23. Aoyama F, Sawaguchi A, Ide S, Kitamura K and Suganuma T: Exfoliation of gastric pit-parietal cells into the gastric lumen associated with a stimulation of isolated rat gastric mucosa in vitro: a morphological study by the application of cryotechniques. Histochem Cell Biol 129: 785-793, 2008.

24. Terracciano LM, Glatz K, Mhawech P, et al: Hepatoid adenocarcinoma with liver metastasis mimicking hepatocellular carcinoma: an immunohistochemical and molecular study of eight cases. Am J Surg Pathol 27: 1302-1312, 2003.

25. Muehlemann M, Miller KD, Dauphinee M and Mizejewski GJ: Review of grow th inhibitory peptide as a biotherapeutic agent for tumor growth, adhesion, and metastasis. Cancer Metastasis Rev 24: 441-467, 2005.

26. Nagai E, Ueyama T, Yao T and Tsuneyoshi M: Hepatoid adenocarcinoma of the stomach. A clinicopathologic and immunohistochemical analysis. Cancer 72: 1827-1835, 1993.

27. Yorita K, Takahashi N, Takai H, et al: Prognostic significance of circumferential cell surface immunoreactivity of glypican-3 in hepatocellular carcinoma. Liver Int 31: 120-131, 2011.

28. Hishinuma M, Ohashi KI, Yamauchi N, et al: Hepatocellular oncofetal protein, glypican 3 is a sensitive marker for alphafetoprotein-producing gastric carcinoma. Histopathology 49: 479-486, 2006.

29. Morford LA, Davis C, Jin L, Dobierzewska A, Peterson ML and Spear BT: The oncofetal gene glypican 3 is regulated in the postnatal liver by zinc fingers and homeoboxes 2 and in the regenerating liver by alpha-fetoprotein regulator 2 . Hepatology 46: 1541-1547, 2007.

30. Nakano K, Orita T, Nezu J, et al: Anti-glypican 3 antibodies cause ADCC against human hepatocellular carcinoma cells. Biochem Biophys Res Commun 378: 279-284, 2009.

31. Ishiguro T, Sugimoto M, Kinoshita Y, et al: Anti-glypican 3 antibody as a potential antitumor agent for human liver cancer. Cancer Res 68: 9832-9838, 2008. 